\title{
Ethnic variation in medial orbital wall anatomy and its implications for decompression surgery
}

Minhui Amy Chan ${ }^{1}$, Farah Ibrahim', Arjunan Kumaran ${ }^{1}$, Kailing Yong ${ }^{1,2,3}$, Anita Sook Yee Chan ${ }^{1,2,3}$ and Sunny Shen ${ }^{1,2,3^{*}}$

\begin{abstract}
Background: To describe the inter-ethnic variation in medial orbital wall anatomy between Chinese, Malay, Indian and Caucasian subjects.

Methods: Single-centre, retrospective, Computed Tomography (CT)-based observational study. 20 subjects of each ethnicity, were matched for gender and laterality. We excluded subjects younger than 16 years and those with orbital pathology. OsiriX version 8.5.1 (Pixmeo., Switzerland) and DICOM image viewing software CARESTREAM Vue PACS (Carestream Health Inc., USA) were used to measure the ethmoidal sinus length, width and volume, medial orbital wall and floor angle and the relative position of the posterior ethmoid sinus to the posterior maxillary wall. Statistical analyses were performed using Statistical Package for Social Sciences version 25.0 (IBM, USA).

Results: There were 12 males (60\%) in each group, with no significant difference in age $(p=0.334-0.994)$. The mean ethmoid sinus length in Chinese, Malay, Indian and Caucasian subjects, using the Chinese as reference, were $37.2,36.9,38.0$ and $37.4 \mathrm{~mm}$, the mean width was $11.6,10.5,11.4$ and $10.0 \mathrm{~mm}(p=0.020)$ and the mean ethmoid sinus volume were $3362,3652,3349$ and $3898 \mathrm{~mm}^{3}$ respectively. The mean medial orbital wall and floor angle was $135.0,131.4,131.0$ and 136.8 degrees and the mean relative position of posterior ethmoid sinus to posterior maxillary wall were $-2.0,-0.2,-1.5$ and $1.6 \mathrm{~mm}(p=0.003)$ respectively.
\end{abstract}

\footnotetext{
* Correspondence: sunny.shen.yu@singhealth.com.sg

${ }^{1}$ Singapore National Eye Centre, Singapore, Singapore

${ }^{2}$ Singapore Eye Research Institute, Singapore, Singapore

Full list of author information is available at the end of the article
}

(c) The Author(s). 2021 Open Access This article is licensed under a Creative Commons Attribution 4.0 International License, which permits use, sharing, adaptation, distribution and reproduction in any medium or format, as long as you give appropriate credit to the original author(s) and the source, provide a link to the Creative Commons licence, and indicate if changes were made. The images or other third party material in this article are included in the article's Creative Commons licence, unless indicated otherwise in a credit line to the material. If material is not included in the article's Creative Commons licence and your intended use is not permitted by statutory regulation or exceeds the permitted use, you will need to obtain permission directly from the copyright holder. To view a copy of this licence, visit http://creativecommons.org/licenses/by/4.0/ The Creative Commons Public Domain Dedication waiver (http://creativecommons.org/publicdomain/zero/1.0/) applies to the data made available in this article, unless otherwise stated in a credit line to the data. 
Conclusions: No inter-ethnic variation was found in decompr
posterior maxillary sinus wall anterior to their posterior ethmoi
Awareness of ethnic variation is essential for safe orbital decor
Keywords: Ethmoid sinus, Maxillary sinus, Orbital decompressi

\section{Background}

Orbital decompression surgery is widely used in the management of severe dysthyroid optic neuropathy (DON) [1]. Other indications include disfiguring exophthalmos, exposure keratopathy from other causes of proptosis and retrobulbar pain [2]. Although many decompression techniques have been described: removing orbital bone or orbital fat or a combination of both, posterior medial orbital wall and posterior orbital floor decompression is still the preferred techniques for relieving apical compression in DON [3].

Medial orbital wall decompression was first described by Sewall in 1936 [4]. Further modifications were made by Walsh and Ogura via a transantral approach for combined medial wall and floor decompression in 1957 [5], and by Kennedy, endoscopically in 1985 [6]. Recent evolution involves sparing of the anterior medial orbital strut during decompression to minimize post-operative diplopia [7].

Traditionally, Lynch incision was used to access the medial orbital wall, however that resulted in significant post-operative scarring [8]. The more recent retrocaruncular approach provides the same exposure as the Lynch incision whilst avoiding the associated scarring [9]. It also allows maximal bone removal near the orbital apex with a more direct exposure of the medial extraperiosteal space [10].

Unlike the extensive literature on surgical techniques, there remains little data on the anatomical variations of the medial orbital wall despite their recognition clinically [11]. The few cadaveric [12, 13], dry skull $[14,15]$ and radiological-based studies $[16,17]$ on medial orbital wall anatomy, have not covered any inter-ethnic variation. Understanding of ethnic variation in medial orbital wall anatomy would improve the safety and efficacy of apical decompression for oculoplastic surgeons and help to identify boundaries for medial wall decompression. Hence, this study sought to describe the medial orbital wall measurements in 80 patients, to evaluate possible inter-ethnic variation.

\section{Methods}

\section{Study design}

Eighty Computed Tomography (CT) orbit scans from our facial trauma database (SNEC Eye Clinic@CGH, Changi General Hospital, Singapore; 2004-2010) were included in the study. Twenty random subjects were selected from each of the four major races in our

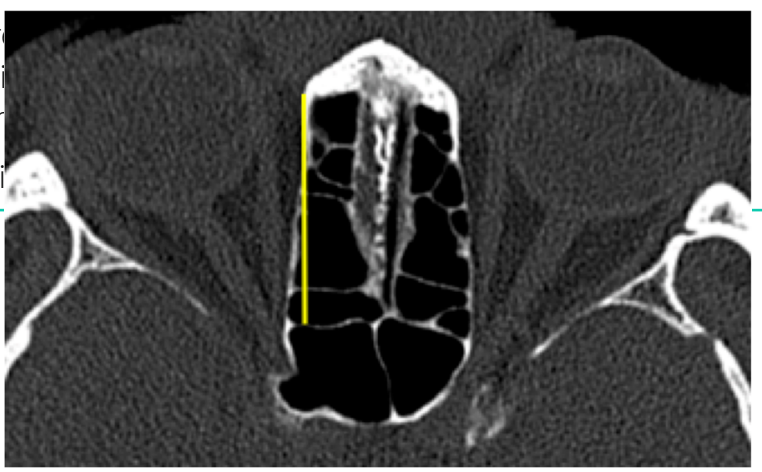

Fig. 1 Ethmoid sinus length

population: Chinese, Malay, Indian and Caucasian. All groups were matched for gender and laterality - with the inclusion of 12 males and 8 females per ethnic group.

We excluded subjects below 16 years of age (with no upper limit for age), patients with other orbital pathology (i.e. Graves orbitopathy, orbital tumours) and the sides with orbital fractures.

All patient identifiers were removed from the scan data during the study. Informed consent was waived by the SingHealth Institutional Review Board (reference number 2016/3134) as the project was a retrospective radiology review with no patient contact and no patient identifiers. This study complied with the tenets of the Declaration of Helsinki and was approved by the SingHealth Institutional Review Board.

\section{Orbital Measurements}

OsiriX version 8.5.1 (Pixmeo., Switzerland) and DICOM image viewing software CARESTREAM Vue PACS (Carestream Health Inc., USA) were used to measure the ethmoid sinus length, width and volume, the medial orbital wall and floor angle and the relation between the ethmoid and maxillary sinuses. All CT orbit scans were performed

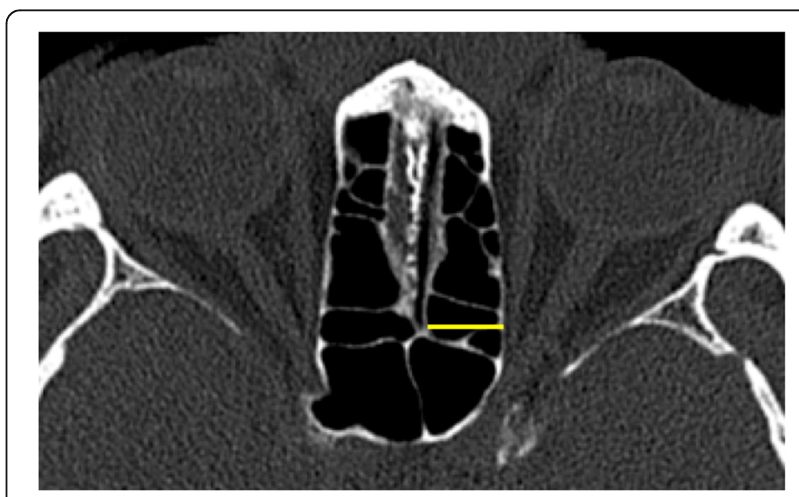

Fig. 2 Ethmoid sinus width 


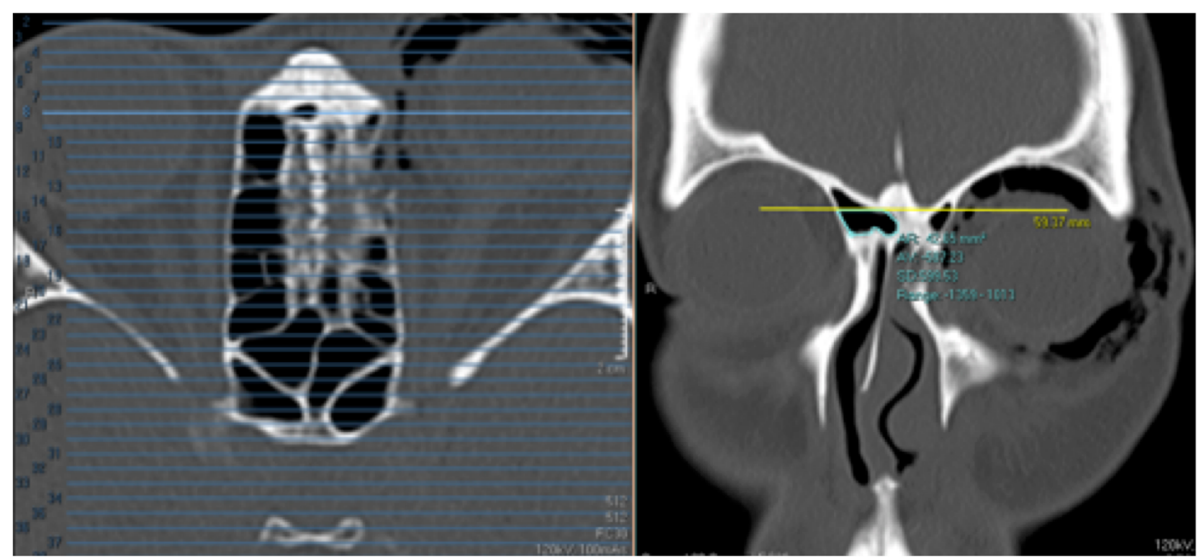

Fig. 3 Ethmoid sinus volume - anterior limit. On the axial view (left image), anterior limit is set at level of posterior lacrimal crest. On the corresponding coronal view (right image), region of interest (ROI) tool is used to mark out the ethmoid sinus volume

by Changi General Hospital's Radiology department using the same standard imaging protocol of $1 \mathrm{~mm}$ cut slices.

\section{Ethmoid sinus length}

On the axial view, the CT slide involving the superior most portion of the optic canal was selected, and the length of the ethmoid sinus was measured (yellow line) (Fig. 1).

\section{Ethmoid sinus width}

On the same axial slide, the largest width of the ethmoid sinus was measured (yellow line) (Fig. 2).

\section{Ethmoid sinus volume}

On both the axial and coronal views, the perimeter of the ethmoid sinus was marked with the Region of Interest (ROI) tool. The anterior limit for ethmoid sinus volume measurement was set at the posterior lacrimal crest and the posterior limit at the anterior face of the sphenoid sinus; the superior limit at the cribriform plate and the inferior limit at the intersection between the medial orbital wall and the orbital floor. The area of the marked segments (volume marked out) were added up to give the total ethmoid sinus volume (Figs. 3, 4 and 5). The ethmoid sinus volume is representative of the maximum decompressible volume during medial orbital wall decompression surgery.

\section{Medial orbital wall and floor angle}

The medial orbital wall and floor angle was measured on the coronal view, at the level of the posterior cortex of the bilateral trigone. The angle was formed between two

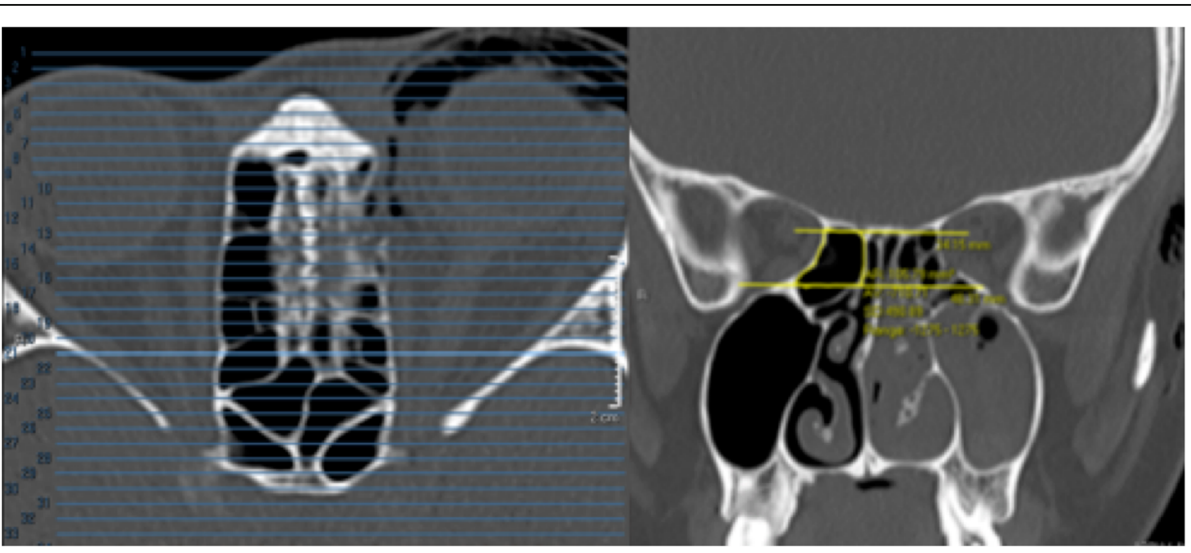

Fig. 4 Ethmoid sinus volume - posterior limit. On the axial view (left image), the posterior limit is set at the anterior face of sphenoid sinus. On the corresponding coronal view (right image), $\mathrm{ROI}$ tool is used to mark out the ethmoid sinus volume 


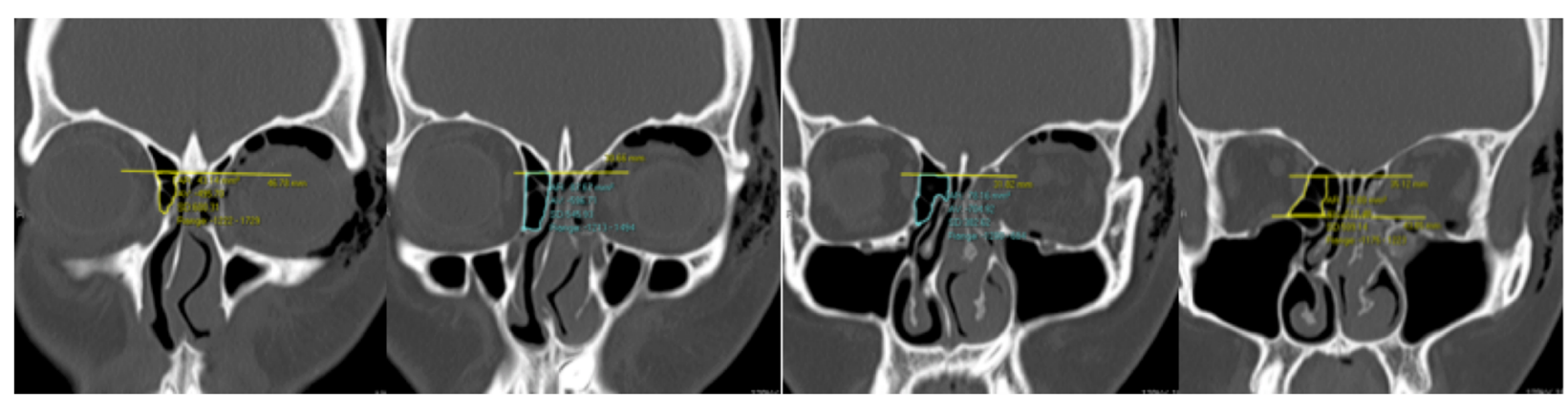

Fig. 5 Ethmoid sinus volume - superior and inferior limits. The superior limit is set at the level of cribriform plate and the inferior limit is set at the intersection between medial orbital wall and orbital floor. Ethmoid sinus volumes are measured from anterior to posterior, with superior and inferior limits in place, and are added up to give the total volume (images below)

lines, one along the medial orbital wall and the other along the orbital floor (Fig. 6).

\section{Olfactory fossa depth}

Using the slide where the cribriform plate is deepest on the coronal view, a horizontal line is drawn connecting both infraorbital nerves. A vertical line is then drawn from the junction of the ethmoid roof to the lateral lamella of the cribriform plate (LLCP) to the marked horizontal line and a separate vertical line is drawn from the cribriform plate to the same horizontal line. The difference between the two vertical lines (yellow lines) signifies the vertical height of the lateral lamella of the cribriform plate (Fig. 7), which is then categorized using Keros' classification. There are 3 Keros categories, namely Keros 1 (1-3mm), Keros 2 (4-7mm) and Keros 3 $(8-16 \mathrm{~mm})[18]$
Relative position of the posterior ethmoid sinus to posterior maxillary wall

On the axial series of scan, we first identified the slide where the posterior maxillary wall is at its most posterior and drew a horizontal line. Using the same technique, we also identified the most posterior of the ethmoid sinus. A vertical line was then drawn between these 2 horizontal lines. A positive value was given if the posterior maxillary walls lay anterior to the posterior ethmoid sinus. A negative value was given if the posterior maxillary wall lay posterior to the posterior ethmoid sinus (Fig. 8).

\section{Reliability indices}

All measurements were done by the First author (AC) twice, 3 months apart, and again independently by the Second author (FI) to assess repeatability and reliability. Inter- and intra-observer variability was

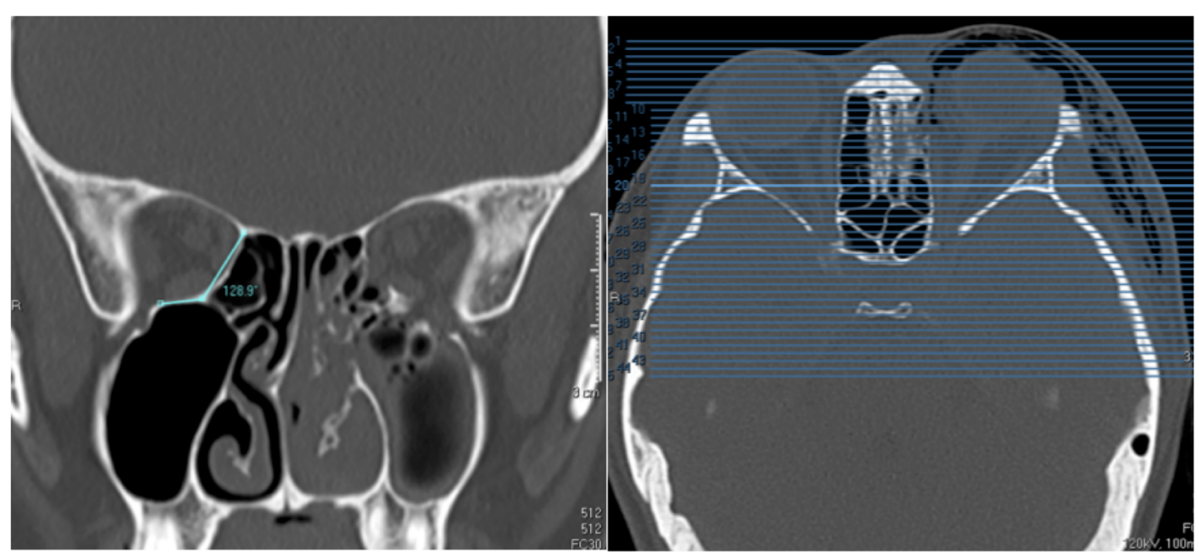

Fig. 6 Medial orbital wall and floor angle. Measured on the coronal view (left image), at the level of posterior cortical bone of the trigones (right image) 


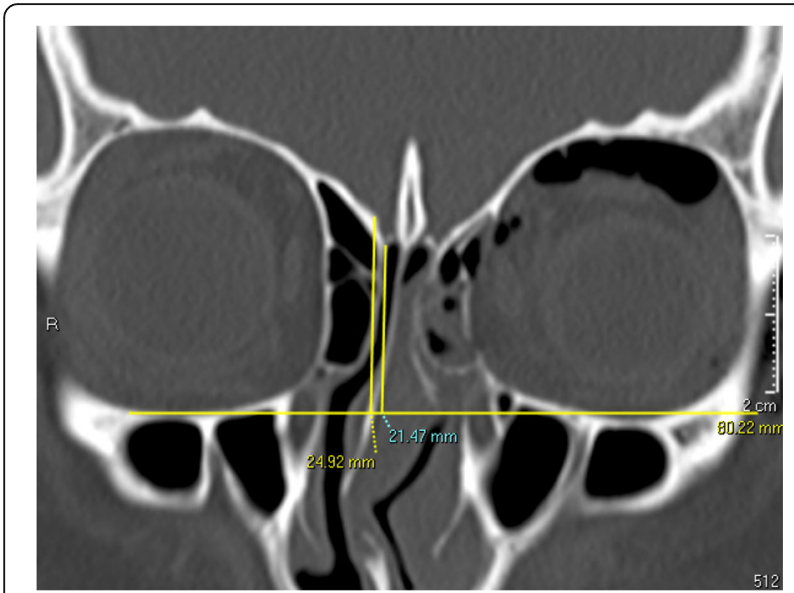

Fig. 7 Olfactory fossa depth. Measured at slide where cribriform plate is deepest, taking the difference between the vertical length to the ethmoid roof and the vertical length to the cribriform plate from a horizontal line connecting both infraorbital nerves

evaluated by Interclass coefficient correlations and Cronbach's alpha.

\section{Statistical analysis}

Data analysis was performed using Statistical Package for Social Sciences (SPSS) version 25 (IBM Corp., Armonk, NY). Descriptive analysis and comparisons between medial orbital wall measurements were evaluated. Two sample t-test was used for comparisons between groups with statistical significance set at $p<0.05$.

\section{Results}

A total of 80 orbit CT scans were included in our study. Each ethnic group (Chinese, Malay, Indian and Caucasian) had 20 subjects, of which $60 \%$ were males $(n=12)$ and $50 \%$ were right sided orbits $(n=10)$. There was no significant difference in the average ages between the groups (refer to Table 1).

The total mean ethmoid sinus length was $37.4 \mathrm{~mm}$ (SD 3.7) and ranged from 27.0 to $45.8 \mathrm{~mm}$. The total mean ethmoid sinus width was $10.9 \mathrm{~mm}$ (SD 2.0) and ranged from 7.5 to $16.1 \mathrm{~mm}$. We noted that the mean ethmoid sinus width was significantly wider in males ( $p$ 0.003) (11.4mm, SD 1.9) as compared to females $(10.1 \mathrm{~mm}, \mathrm{SD}$ 1.9). There were otherwise no statistically significant differences noted with regard to ethmoid sinus length, volume and other orbital measurements between both genders (refer to Table 2).

Between the different racial groups, there was no statistically significant difference in the mean ethmoid sinus length. As compared to Chinese (11.6mm, SD 2.2), Caucasians had a narrower ethmoid sinus width (10.0mm SD 1.8, $p=0.020)$. There was otherwise no statistically significant difference in the ethmoid sinus width between Chinese, Malay and Indian subjects (refer to Table 3).

The mean ethmoid sinus volume was $3565 \mathrm{~mm}^{3}$ (SD 909), with a range of 1892 to $5818 \mathrm{~mm}^{3}$ (Table 2). However, amongst the racial groups, there was no statistically significant difference in the ethmoid sinus volume ( $p$-value of $0.271 ; 0.964 ; 0.102$ ) (Fig. 9).

We noted the average medial orbital wall and floor angle to be 133.5 degrees (SD 9.9) with a range of 109.6 to 163.0 degrees (Table 2). Similarly, no ethnic variation was noted with regard to the medial orbital wall and floor angle (p-value of 0.223; 0.148; 0.560) (Fig. 10).

There were significantly more Caucasians ( $p$-value $0.010)$ with shorter olfactory fossae depths compared to the Chinese. $60 \%$ of Caucasians had Keros 2 olfactory fossa depth. None of the subjects fulfilled the Keros 3 classification (refer to Table 4).

With regard to the relative position of posterior ethmoid sinus to posterior maxillary sinus wall, in

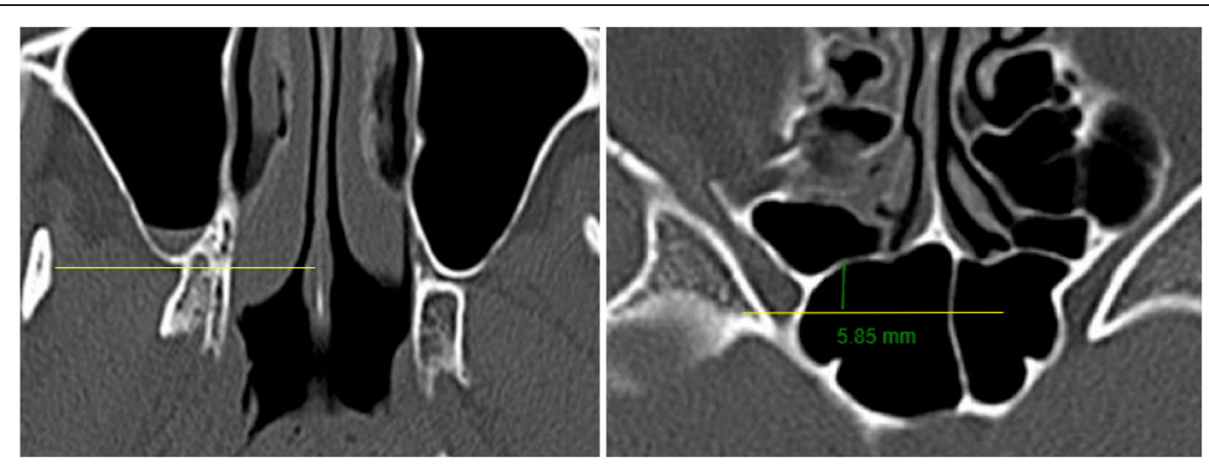

Fig. 8 Relative position of posterior ethmoid sinus to posterior maxillary wall. Using the slide where the posterior maxillary wall is at its most posterior position, a horizontal line is drawn (yellow). A vertical line (green) is then drawn and measured from this horizontal line to the most posterior aspect of ethmoidal sinus. A positive value was given if the posterior maxillary wall lay anterior to the posterior ethmoidal wall. A negative value was given if the posterior maxillary sinus wall lay posterior to the posterior ethmoidal wall 
Table 1 Demographics

\begin{tabular}{|c|c|c|c|c|c|c|c|c|}
\hline & Chines & & Malay & & Indiar & & Cauce & \\
\hline & & $p$-value ${ }^{\#}$ & & $p$-value ${ }^{\#}$ & & $p$-value ${ }^{\#}$ & & $p$-value ${ }^{\#}$ \\
\hline Total number & 20 & & 20 & & 20 & & 20 & \\
\hline Males & 12 & & 12 & & 12 & & 12 & \\
\hline Laterality, right & 10 & & 10 & & 10 & & 10 & \\
\hline Minimum age, years & 18 & & 21 & & 17 & & 28 & \\
\hline $\begin{array}{l}\text { Mean age, years } \\
\left(\mathrm{SD}^{*}\right)\end{array}$ & $\begin{array}{l}42.4 \\
(18.7)\end{array}$ & - & $\begin{array}{l}42.3 \\
(20.4)\end{array}$ & 0.994 & $\begin{array}{l}42.7 \\
(14.8)\end{array}$ & 0.948 & $\begin{array}{l}47.4 \\
(13.5)\end{array}$ & 0.334 \\
\hline
\end{tabular}

*Standard deviation (SD)

"compared to Chinese subjects

Caucasians, the posterior maxillary wall was anterior to the posterior ethmoid wall / anterior face of sphenoid (1.6mm, SD 3.3, p-value 0.003), whereas in Chinese, Malay and Indians the posterior maxillary wall was further back compared to the posterior ethmoid wall (Table 5).

Inter and intra-observer variability are summarized below in Table 6.

\section{Discussion}

In today's cosmopolitan society, it is not uncommon to have patients from different ethnic backgrounds. Even though variation in orbital anatomy is well recognised clinically, published data on ethnic variation is limited.

In our earlier study on lateral orbital wall anatomy [19], we have demonstrated that Indians, and to a lesser extent Caucasians, have smaller lateral wall trigones as compared to Chinese and Malays. This explains why lateral orbital decompression is technically more difficult in Chinese and Malay patients and often requires powered instruments. Indians also have shallower orbits which may limit the efficacy of lateral orbital decompression alone in reducing proptosis.

For patients with DON or severe proptosis in which lateral orbital decompression alone is ineffective or insufficient, removal of the medial orbital wall and/or orbital floor is required. In this study, we evaluate the medial orbital wall anatomy and its ethnic variations.

We recorded ethmoid sinus lengths ranging from $29.2-45.8 \mathrm{~mm}$ in males and $27.0-44.0 \mathrm{~mm}$ in females (Table 2), which were comparable to the existing literature $(38.8-42.5 \mathrm{~mm}$ in males and $36.4-40.8 \mathrm{~mm}$ in females) [20]. There was no statistically significant difference between the ethnic groups. As a surrogate for the medial orbital wall, the mean ethmoid sinus length is rather constant and provides a reliable estimate on how deep a surgeon needs to decompress to relieve the apical crowding.

For the ethmoid sinus width, we were unable to compare our results (total mean width $10.9 \mathrm{~mm}, 7.5$ $16.1 \mathrm{~mm}$ in females, $8.2-15.5 \mathrm{~mm}$ in males) with the published literature $(15.1-17.5 \mathrm{~mm}$ in males, 13.4$16.0 \mathrm{~mm}$ in females) due to differences in

Table 2 Gender specific and total mean medial orbital wall measurements

\begin{tabular}{|c|c|c|c|c|c|c|c|c|}
\hline & \multicolumn{3}{|l|}{ Male } & \multicolumn{3}{|l|}{ Female } & \multicolumn{2}{|l|}{ Total } \\
\hline & Mean & $p$-value ${ }^{\#}$ & Range & Mean & $p$-value ${ }^{\#}$ & Range & Mean & Range \\
\hline $\begin{array}{l}\text { Length, } \\
\mathrm{mm}\left(\mathrm{SD}^{*}\right)\end{array}$ & $37.6(3.4)$ & - & $29.2-45.8$ & $37.0(4.1)$ & 0.445 & $27.0-44.0$ & $37.4(3.7)$ & $27.0-45.8$ \\
\hline Width, mm (SD*) & $11.4(1.9)$ & - & $8.2-15.5$ & $10.1(1.9)$ & 0.003 & $7.5-16.1$ & $10.9(2.0)$ & $7.5-16.1$ \\
\hline $\begin{array}{l}\text { Volume, } \\
\mathrm{mm}^{3} \\
\left(\mathrm{SD}^{*}\right)\end{array}$ & 3718 (862) & - & $2120-5818$ & $3336(942)$ & 0.065 & $1892-5267$ & 3565 (909) & $1892-5818$ \\
\hline $\begin{array}{l}\text { Medial orbital wall and floor } \\
\text { angle, degrees (SD*) }\end{array}$ & $134.6(10.1)$ & - & $116.1-163.0$ & $131.9(9.6)$ & 0.236 & 109.6-149.1 & $133.5(9.9)$ & 109.6-163.0 \\
\hline $\begin{array}{l}\text { Relative position of posterior } \\
\text { ethmoid sinus to posterior } \\
\text { maxillary wall, } \\
\mathrm{mm}\left(\mathrm{SD}^{*}\right)\end{array}$ & $-0.2(4.5)$ & - & $-12.9-8.2$ & $-1.0(4.0)$ & 0.398 & $-9.4-7.7$ & $-0.5(4.3)$ & $-12.8-8.21$ \\
\hline
\end{tabular}

*Standard deviation (SD)

\#compared to male subjects 
Table 3 Mean Ethmoid Sinus Length and Width

\begin{tabular}{|c|c|c|c|c|c|c|c|c|}
\hline \multirow[b]{2}{*}{ Mean } & \multicolumn{2}{|l|}{ Chinese } & \multicolumn{2}{|l|}{ Malays } & \multicolumn{2}{|l|}{ Indians } & \multicolumn{2}{|c|}{ Caucasians } \\
\hline & & $p$-value $\#$ & & $p$-value ${ }^{\#}$ & & $p$-value ${ }^{\#}$ & & $p$-value \\
\hline $\begin{array}{l}\text { Length, } \\
\mathrm{mm}\left(\mathrm{SD}^{*}\right)\end{array}$ & $37.2(4.6)$ & - & $36.9(1.0)$ & 0.844 & $38.0(3.0)$ & 0.514 & $37.4(0.7)$ & 0.844 \\
\hline Width, mm (SD*) & $11.6(2.2)$ & - & $10.5(1.7)$ & 0.086 & $11.4(1.7)$ & 0.711 & $10.0(1.8)$ & 0.020 \\
\hline
\end{tabular}

*Standard deviation (SD)

\# compared to Chinese subjects

measurement methods [20]. Males were noted to have wider mean ethmoid sinuses than females in our study and in existing literature [20]. Additionally, Caucasians were noted to have narrower ethmoid sinuses in our study as compared to the Chinese.

With regard to ethmoid sinus volume, our average measurement was $3.6 \mathrm{~cm}^{3}\left(3.7 \mathrm{~cm}^{3}\right.$ in males and $3.3 \mathrm{~cm}^{3}$ in females) and was most similar to the total mean of $4.51 \mathrm{~cm}^{3}$ found in a Korean population by Park et al. [17]. There were published data of bigger ethmoid sinus volumes of $5.5 \mathrm{~cm}^{3}$ (females) and $6.3 \mathrm{~cm}^{3}$ (males) in a Turkish population [16] and total mean volume of $5.5 \mathrm{~cm}^{3}$ in a Spanish population [21]. However, our study focused on the clinically decompressible ethmoid sinus volume from a retrocarcuncular approach instead of total ethmoidal volume and thus had smaller measured volumes.

Although the coronal slide we chose for measuring the medial orbital wall and floor angle may seem anterior to the true orbital apex, our measuring technique reduces the impact of sphenoid sinus size and location, which occasionally forms the medial wall of the optic canal and is not routinely removed in decompression surgery. Our mean angle value of $133.5^{\circ}$ was close to Kang et al.'s $136.88^{\circ}$ which was derived from 276 Asian orbits [22]. It is also similar to the $122^{\circ}$ measured by Keast et al. in 36 Polynesian and $119^{\circ}$ in 144 Caucasians [23]. This relative consistency in medial orbital wall and floor angle, reassured us of a minimum 4 clock hours wide apical relief in adequate posterior decompression surgery.

The olfactory fossa depth and Keros classification, guides us with the extent of superior bone removal in medial wall decompression. In our study, we noted an inclination towards Keros 2 in Caucasians as compared to the Chinese, differing from Badia, et al., who found no significant differences in olfactory depth between 100 Caucasians and 100 Chinese subjects [24]. This discrepancy may be due to our small sample size. However, our results concurred with Alazzawai, et al., where no significant differences were found between the Chinese, Malay and Indians in their Malaysian population with $80 \%$ Keros 1 classification in 300 subjects, with none fulfilling Keros 3 criteria [25]. In Keros 3 patients, their ethmoidal roofs lie significantly higher than the cribriform plate, and thus bear the greatest risk of inadvertent intracranial entry during medial wall decompression [26].

Before the age of fine-cut CT scan and image-guided surgery, age-old wisdom suggested that the posterior ethmoidal wall (i.e. anterior sphenoid face) is about $1 \mathrm{~cm}$

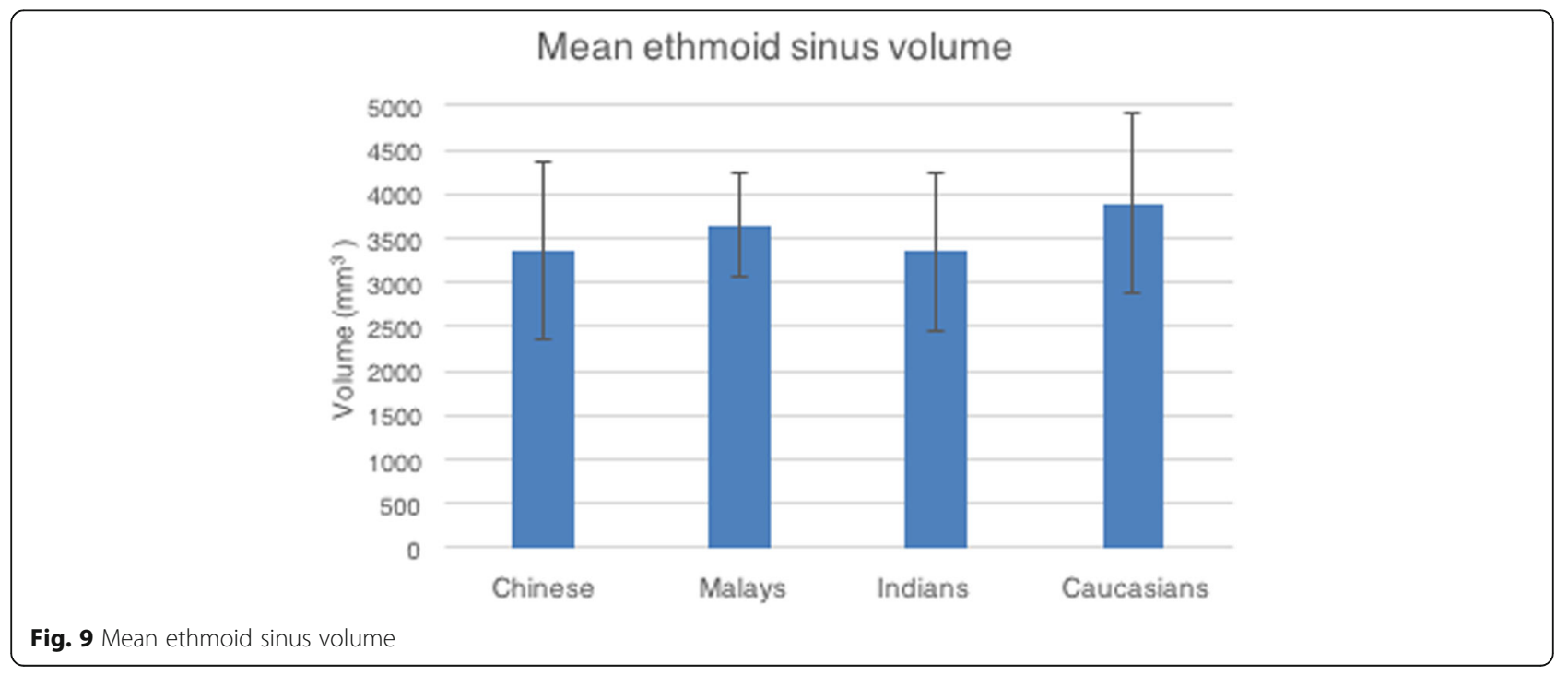




\section{Mean medial orbital wall and floor angle}

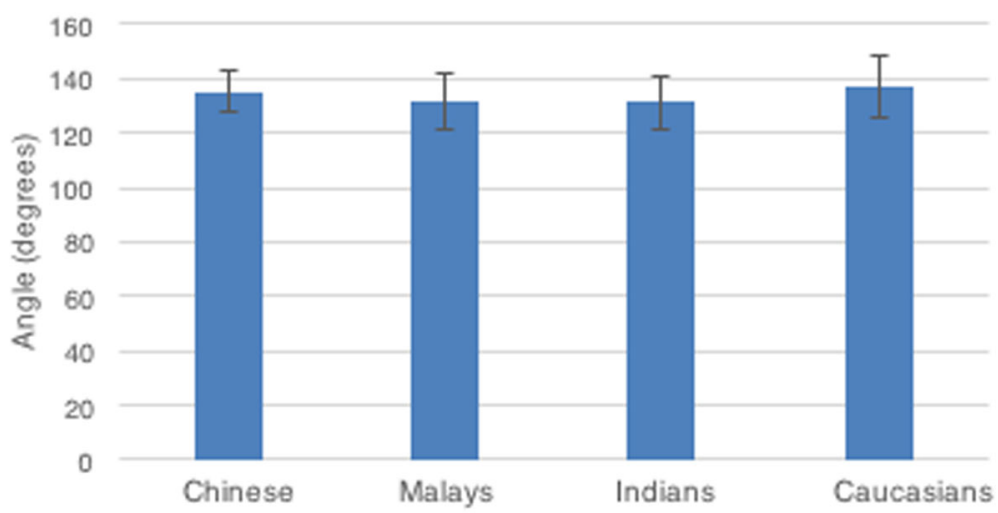

Fig. 10 Mean medial orbital wall and floor angle

behind the posterior maxillary wall. To prevent accidental entry into the sphenoid sinus and damaging the carotid syphon, one must sound out the posterior maxillary wall as a guide to see how far back decompression along the medial wall is needed (i.e. removing all the posterior ethmoid sinus until the anterior sphenoid face). In our study, we noted only Caucasians had their mean posterior maxillary wall anterior to the posterior ethmoidal wall / anterior sphenoid face. To our knowledge, there is only one other study, with 11 cadavers, where the anterior face of the sphenoid was noted to be about $2-4 \mathrm{~mm}$ more posterior than the posterior maxillary wall [27]. For the Chinese, Malays and Indians in our study, their posterior ethmoidal wall is anterior to the posterior maxillary wall. This finding is similar to another Korean radiological study [28] of 115 CT scans, albeit with different measurement methods. This knowledge of ethnic variation in relative position of anterior sphenoid face to posterior maxillary wall is important in defining the safe zone of decompression. In reality, the

Table 4 Mean Keros length (vertical depth of olfactory fossa) and type

\begin{tabular}{|c|c|c|c|c|c|c|c|c|}
\hline \multirow[b]{2}{*}{ Mean } & \multicolumn{2}{|c|}{ Chinese } & \multicolumn{2}{|c|}{ Malays } & \multicolumn{2}{|c|}{ Indians } & \multicolumn{2}{|c|}{ Caucasians } \\
\hline & & $p$-value & & $p$-value ${ }^{\#}$ & & $p$-value ${ }^{\#}$ & & $p$-value \\
\hline $\begin{array}{l}\text { Keros } \\
\text { length, } \\
\mathrm{mm} \\
\left(\mathrm{SD}^{*}\right)\end{array}$ & $\begin{array}{l}3.1 \\
(0.8)\end{array}$ & - & $\begin{array}{l}2.9 \\
(0.7)\end{array}$ & 0.329 & $\begin{array}{l}3.1 \\
(0.8)\end{array}$ & 0.949 & $\begin{array}{l}4.0 \\
(1.2)\end{array}$ & 0.010 \\
\hline Keros 1 & 18 & - & 18 & - & 16 & - & 8 & - \\
\hline Keros 2 & 2 & - & 2 & - & 4 & - & 12 & - \\
\hline Keros 3 & 0 & - & 0 & - & 0 & - & 0 & - \\
\hline
\end{tabular}

*Standard deviation (SD)

** Keros type 1: 1-3mm, Keros type 2: 4-7mm; Keros type 3: 8-16mm

"compared to Chinese subjects sphenoidal wall is often thicker than the posterior ethmoidal wall, surgeons should think twice if they find the posterior medial orbital wall more difficult to break during decompression and when they are about 3-4 $\mathrm{cm}$ beyond the posterior lacrimal crest (i.e. mean ethmoid length) or $3-4 \mathrm{~mm}$ from the posterior maxillary wall.

There were a few limitations in our study. Firstly, the sample size was relatively small and could have benefited from a larger number of subjects to allow for more accurate results. For example, we noted that Caucasians had larger ethmoid sinus volumes as compared to the Chinese but it did not reach statistical significance.

Secondly, the different ethnic groups may not be a completely homogenous sample, as there might have been Malays of Arab or of mixed Arab heritage, Chinese of Northern and Chinese of Southern descent for example.

Lastly, ethmoidal sinus anatomy is highly complex, despite the various methods used to demarcate and measure its volume, there remains much difficulty and variability in defining the boundaries of these intricate air cells [29]. We had strict and easily recognizable limits for demarcating the ethmoid sinus area for calculation and ensured that measurements were repeated twice by one observer and repeated again by a second observer to safeguard the reproducibility of the ethmoid sinus

Table 5 Mean relative position of posterior ethmoid sinus to posterior maxillary wall

\begin{tabular}{|c|c|c|c|c|c|c|c|c|}
\hline \multirow[b]{2}{*}{ Mean } & \multicolumn{2}{|c|}{ Chinese } & \multicolumn{2}{|c|}{ Malays } & \multicolumn{2}{|c|}{ Indians } & \multicolumn{2}{|c|}{ Caucasians } \\
\hline & & $p$-value ${ }^{\#}$ & & $p$-value ${ }^{\#}$ & & $p$-value ${ }^{\#}$ & & $p$-value ${ }^{\#}$ \\
\hline $\begin{array}{l}\text { Difference } \\
\text { in length, }\end{array}$ & $\begin{array}{l}-2.0 \\
(3.9)\end{array}$ & - & $\begin{array}{l}-0.2 \\
(3.1)\end{array}$ & 0.100 & $\begin{array}{l}-1.5 \\
(5.8)\end{array}$ & 0.730 & $\begin{array}{l}1.6 \\
(3.2)\end{array}$ & 0.003 \\
\hline
\end{tabular}

$\mathrm{mm}\left(\mathrm{SD}^{*}\right)$

*Standard deviation (SD)

"compared to Chinese subjects 
Table 6 Reliability Indices of all measurements

\begin{tabular}{llll}
\hline & & \multicolumn{2}{l}{ Intraclass Correlation (95\% Cl) } \\
\cline { 3 - 4 } & $\begin{array}{l}\text { Cronbach's } \\
\text { alpha }\end{array}$ & Intra-user & Inter-user \\
\hline Ethmoidal length & 1.000 & 1.000 & 1.000 \\
Ethmoidal width & 1.000 & 1.000 & 1.000 \\
Ethmoidal volume & 1.000 & 0.999 & 1.000 \\
$\begin{array}{l}\text { Medial orbital wall } \\
\text { and floor angle }\end{array}$ & 1.000 & 0.999 & 0.999 \\
$\begin{array}{l}\text { Relative position of } \\
\text { posterior ethmoid }\end{array}$ & 0.988 & 0.983 & 0.976 \\
$\begin{array}{l}\text { sinus to posterior } \\
\text { maxillary wall }\end{array}$ & & & \\
\hline
\end{tabular}

volume. On analysis, we found good inter and intrauser agreement with all our medial orbital wall measurements.

The strengths of our study include building on the same platform as earlier study on lateral orbital wall anatomy. Besides providing ethnic specific anatomical data for 4 different races, we explored the potential inter-ethnic variations in orbital wall anatomy, for which there is a dearth of literature on.

Future research in this area could expand on increasing the sample size and by involving other ethnic groups. Alternatively, the focus could also be shifted towards soft tissues measurements in normal or patients with preexisting DON. This would allow for potential discovery of inter-ethnic pathological changes.

\section{Conclusions}

There was no statistically significant inter-ethnic difference in ethmoid sinus length, decompressible ethmoid sinus volume and medial orbital wall and floor angle. Caucasians were found to have smaller ethmoid sinus widths and had a more anteriorly located posterior maxillary wall relative to their posterior ethmoidal wall, unlike the Chinese, Malay and Indians. Better awareness of some anatomical consistencies and ethnic variation in orbital anatomy is essential for safe orbital decompression surgery.

\section{Abbreviations}

CT: Computed tomography; DON: Dysthyroid optic neuropathy; ROI: Region of Interest; LLCP: Lateral lamella of the cribriform plate; SPSS: Statistical Package for Social Sciences

\section{Acknowledgements}

Not applicable.

\section{Authors' contributions}

$\mathrm{AC}$ acquired the data and drafted the manuscript, $\mathrm{FI}$ and $\mathrm{AK}$ acquired the data, KY, SS and ACSY revised the manuscript. The author(s) read and approved the final manuscript.

\section{Funding}

Funded by SERI VisionSave - Translational Ophthalmic Pathology Platform.
Availability of data and materials

The dataset supporting the conclusions of this article is included within the article and its additional file.

\section{Declarations}

\section{Ethics approval and consent to participate}

Informed consent was waived by the SingHealth Institutional Review Board as the project was a retrospective radiology review with no patient contact and no patient identifiers. This study complied with the tenets of the Declaration of Helsinki and was approved by the SingHealth Institutional Review Board.

\section{Consent for publication}

Not applicable.

\section{Competing interests}

The authors declare that they have no competing interests.

\section{Author details}

${ }^{1}$ Singapore National Eye Centre, Singapore, Singapore. ${ }^{2}$ Singapore Eye Research Institute, Singapore, Singapore. ${ }^{3}$ Ophthalmology and Visual Sciences Academic Clinical Program, SingHealth Duke-NUS Academic Medical Centre, Singapore, Singapore.

Received: 14 November 2020 Accepted: 22 March 2021

Published online: 29 July 2021

\section{References}

1. McKeag D, Lane C, Lazarus J, et al. Clinical features of dysthyroid optic neuropathy: a European Group on Graves' Orbitopathy (EUGOGO) survey. Br J Ophthalmol. 2007; 91:455-8.

2. Bartalena $\mathrm{L}$, Baldeschi $\mathrm{L}$, Dickinson $\mathrm{A}$, et al. Consensus statement of the European Group on Grave' s orbitopathy (EUGOGO) on management of GO. Eur J Endocinol. 2008; 158(3):273-85.

3. Verity D, Rose G. Acute thyroid eye disease (TED): Principles of medical and surgical management. Eye. 2013; 27:308-19.

4. Mehta P, Durrani O. Outcome of deep lateral wall rim-sparing orbital decompression in thyroid-associated orbitopathy: a new technique and results of a case series. Orbit. 2011; 30:265-8.

5. Walsh T, Ogura J. Transantral orbital decompression for malignant exophthalmos. Laryngoscope. 1957; 67:544-568.

6. Kennedy D. Functional endoscopic sinus surgery: technique. Arch Otolaryngol. 1985; 110(10):643-649.

7. O'Malley M, Meyer D. Transconjunctival fat removal combined with conservative medial wall/floor orbital decompression for Graves orbitopathy. Ophthal Plast Reconstr Surg. 2009; 25:206-10.

8. Harrison D. Surgical approach to the medial orbital wall. Ann Otol Rhinol Laryngol. 1981; 90(5):415-419.

9. Shorr N, Baylis H, Goldberg R, Perry J. Transcaruncular approach to the medial orbit and orbital apex. Ophthalmology. 2000; 107(8):1459-1463.

10. Liao S, Tien C, Lin L. Transcaruncular Orbital Decompression: An Alternate Procedure for Graves Ophthalmopathy With Compressive Optic Neuropathy. Am J Ophthalmol. 2006; 141(5):810-818.

11. Kamer L, Noser H, Schramm A, et al. Anatomy-Based Surgical Concepts for Individualized Orbital Decompression Surgery in Graves Orbitopathy. I. Orbital Size and Geometry. Ophthal Plast Reconstr Surg. 2010; 26(5): 348-352.

12. Abuzayed B, Tanriover N, Gazioglu N, et al. Endoscopic endonasal approach to the orbital apex and medial orbital wall: anatomic study and clinical applications. J Craniofac Surg. 2009; 20(5):1594-1600.

13. Morales-Avalos R, Santos-Martínez A, Ávalos-Fernández C, et al. Clinical and surgical implications regarding morphometric variations of the medial wall of the orbit in relation to age and gender. Eur Arch Otorhinolaryngol. 2016; 273(9):2785-2793.

14. Karakaş P, Bozkır M, Oguz Ö. Morphometric measurements from various reference points in the orbit of male Caucasians. Surg Radiol Anat. 2002; 24(6):358-362.

15. Abed $S$, Shams $P$, Shen $S$, et al. A cadaveric study of ethmoidal foramina variation and its surgical significance in Caucasians. Br J Ophthalmol. 2012; 96(1):118-121. 
16. Emirzeoglu M, Sahin B, Bilgic S, et al. Volumetric evaluation of the paranasal sinuses in normal subjects using computer tomography images: a stereological study. Auris Nasus Larynx. 2007; 34(2):191-195.

17. Park I, Song J, Choi H, et al. Volumetric study in the development of paranasal sinuses by CT imaging in Asian: a pilot study. Int J Paediatr Otorhinolaryngol. 2010; 74(12):1347-1350.

18. Keros P. On the practical importance of differences in the level of the cribriform plate of the ethmoid. Laryngol Otol. 1965; 41:808-13.

19. Kumaran A, Chan A, Yong K, Shen S. Ethnic variation in deep lateral orbital anatomy and its implications on decompression surgery, Orbit. 2019; 38:2, 95-102.

20. Spaeth J, Krügelstein U, Schlöndorf G. The paranasal sinuses in CT-imaging: development from birth to age 25. Int J Pediatr Otorhinolaryngol. 1997; 39(1):25-40

21. Fernandez J, Escuredo J, Del Rey A, Montoya F. Morphometric study of the paranasal sinuses in normal and pathological conditions. Acta Otolaryngol. 2000; 120(2): 273-278.

22. Kang H, Han J, Oh H, et al. Anatomical Studies of the Orbital Cavity Using Three-Dimensional Computed Tomography. J Craniofac Surg. 2016; 27(6): 1583-1588.

23. Keast $A$, Sofie $Y$, Dawes $P$, Lyons $B$. Anatomical variations of the paranasal sinuses in Polynesian and New Zealand European computerized tomography scans. Otolaryngol. 2008; 139(2), 216-221.

24. Badia L, Lund V, Wei W, et al. Ethnic variation in sinonasal anatomy on CTscanning. Rhinology. 2005; 43(3):210.

25. Alazzawi S, Omar R, Rahmat $\mathrm{K}$, et al. Radiological analysis of the ethmoid roof in the Malaysian population. Auris Nasus Larynx. 2012; 39(4):393-396.

26. Gauba V, Saleh G, Dua G, et al. Radiological classification of anterior skull base anatomy prior to performing medial orbital wall decompression. Orbit. 2006; 25(2):93-96.

27. Casiano R. A stepwise surgical technique using the medial orbital floor as the key landmark in performing endoscopic sinus surgery. Laryngoscope. 2001; 111(6): 964-974

28. Lee $\mathrm{S}$. The relationship of the medial roof and the posterior wall of the maxillary sinus to the sphenoid sinus: a radiologic study. Braz J Otorhinolaryngol. 2017; 83(4): 375-380.

29. Márquez S, Tessema B, Clement P, et al. Development of the ethmoid sinus and extramural migration: the anatomical basis of this paranasal sinus. Anat Rec. 2008; 291(11):1535-1553.

\section{Publisher's Note}

Springer Nature remains neutral with regard to jurisdictional claims in published maps and institutional affiliations.

Ready to submit your research? Choose BMC and benefit from:

- fast, convenient online submission

- thorough peer review by experienced researchers in your field

- rapid publication on acceptance

- support for research data, including large and complex data types

- gold Open Access which fosters wider collaboration and increased citations

- maximum visibility for your research: over $100 \mathrm{M}$ website views per year

At $\mathrm{BMC}$, research is always in progress.

Learn more biomedcentral.com/submissions 